\title{
Orofacial dermoid cysts in pediatric patients: A review of 8 cases
}

\author{
Cristina Bonet-Coloma ${ }^{1}$, Ignacio Mínguez-Martínez ${ }^{2}$, Cristina Palma-Carrió ${ }^{3}$, B Ortega-Sánchez ${ }^{1}$, María \\ Peñarrocha-Diago ${ }^{4}$, Juan-Manuel Mínguez-Sanz ${ }^{5}$
}

\footnotetext{
${ }^{1}$ Master of Oral Surgery and Implantology, Valencia University Medical and Dental School, Valencia, Spain

${ }^{2}$ Master of Oral Surgery and Implantology, Professor of Oral Surgery. Cardenal Herrera-CEU University, Valencia, Spain

${ }^{3}$ Student of Master of Oral Surgery and Implantology, Valencia University Medical and Dental School, Valencia, Spain

${ }^{4}$ Professor Assistant of Oral Surgery. Master of Oral Surgery and Implantology, Valencia University Medical and Dental School, Valencia, Spain

${ }^{5}$ Head Service of Maxillofacial Surgery, University La Fe Hospital, Valencia, Spain
}

Correspondence:

Clínica Odontológica

Gascó Oliag, 1

46021-Valencia (Spain)

maria.penarrocha@uv.es

Received: 27/02/2010

Accepted: $27 / 06 / 2010$
Bonet-Coloma C, Mínguez-Martínez I, Palma-Carrió C, Ortega-Sánchez B, Peñarrocha-Diago MA, Mínguez-Sanz JM. Orofacial dermoid cysts in pediatric patients: A review of 8 cases. Med Oral Patol Oral Cir Bucal. 2011 Mar 1;16 (2):e200-3.

http://www.medicinaoral.com/medoralfree01/v16i2/medoralv16i2p200pdf

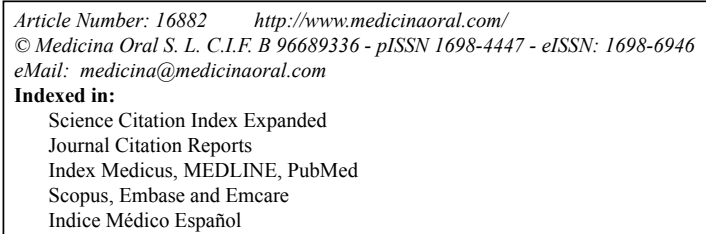

\begin{abstract}
Objective: The aim was to analyze the clinical characteristics, treatment and outcome of 8 orofacial dermoid cysts (DC) in pediatric patients.

Material and Methods: A retrospective observational study was made, reviewing the medical records with clinical diagnosis of dermoid cyst between 1987 and 2006 in the Children's Maxillofacial Surgery Department of the Hospital Universitario La Fe, Valencia, Spain. The following data were collected: sex, age, location, size and duration of the lesion, treatment, length of follow-up, and recurrence.

Results: Eight patients ( 3 girls and 5 boys) with a mean age of 2.7 years (range $0-12$ years). Four DC were located in the oral area ( 3 sublingual and 1 lingual), one in the periorbital and three in the nasal areas. The size ranged from $0.8 \mathrm{~cm}$ to $4 \mathrm{~cm}$. The mean duration of the lesion was 13.7 months (range 4 days to 2 years). All DC were diagnosed pathologically following surgical removal of the lesion. There were no recurrences.

Conclusion: The appearance of DC in the maxillofacial region of pediatric patients is uncommon. The floor of the mouth is the most frequently affected area in the oral cavity. Treatment is surgical removal of the lesion. Recurrence is unusual.
\end{abstract}

Key words: Oral dermoid cyst, dermoid cyst in children. 


\section{Introduction}

Dermoid cysts (DC) are benign lesions arising from entrapment of epithelial rests during embryogenesis (1). They rarely present in children, and are usually diagnosed during the 2 nd or 3rd decade of life (2). In the head and neck region they occur most frequently in the periorbital area $(3,4)$; while $6.5 \%$ of dermoid cysts in this region present in the oral cavity (5), where the most common site is the floor of the mouth. Other less frequent locations have been described, such as the tongue (6), the parotid gland (7) and the mandible (8). The treatment of choice is surgical excision. Recurrence of the lesion is unusual (4).

The aim of this study was to analyze the clinical characteristics, treatment and outcome of orofacial DC in 8 children.

\section{Materials and Methods}

A retrospective observational study was performed, reviewing the medical records with clinical diagnosis of DC between 1987 and 2006 in the Children's Maxillofacial Surgery Department of the Hospital Universitario La Fe, Valencia, Spain (age 0-14 years). Patients with clinical and pathological diagnosis of DC in the orofacial area were included.

Data regarding sex, age, location and size of the lesion, duration (time since appearance of the lesion until date of diagnosis), treatment, length of follow-up (from the date of diagnosis to date of discharge or last revision) and recurrence were recorded for all patients.
All patients underwent surgery under general anesthesia for removal of the lesion by maxillofacial surgeons. The surgical approach varied according to the size and location of the lesion. All lesions were analyzed histopathologically at the Department of Pathology.

\section{Results}

The records of 12 patients with clinical diagnosis of DC were reviewed. Four cases were excluded ( 2 because the pathological diagnosis did not confirm the diagnosis of DC and 2 for incomplete records). Eight patients (3 girls and 5 boys) aged $0-12$ years with a mean age of 2.7 years were included in the study (Table 1). Seven DC were diagnosed before 3 years of age, three of these at birth. Four DC were located in the oral region (3 sublingual and 1 lingual), 1 in the periorbital and 3 in the nasal areas (Fig.1). The mean diameter of the lesion was $1.7 \mathrm{~cm}$

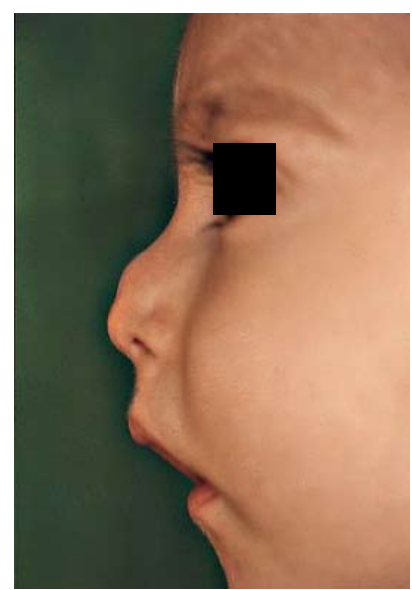

Fig. 1. Case 7: DC in the nasal dorsum.

Table 1. Orofacial dermoid cysts in pediatric patients.

\begin{tabular}{|c|c|c|c|c|c|c|c|c|}
\hline Case No & Age & Sex & Neonatal & Location & $\begin{array}{c}\text { Size } \\
(\mathbf{c m})\end{array}$ & $\begin{array}{c}\text { Duration } \\
\text { (months) }\end{array}$ & R & $\begin{array}{c}\text { Follow-up } \\
\text { (months) }\end{array}$ \\
\hline $\mathbf{1}$ & 2 years & G & No & Periorbital & 1.5 & 4 & No & 1 \\
\hline $\mathbf{2}$ & 3 years & B & Yes & Nasal & 1.5 & 36 & No & 1 \\
\hline $\mathbf{3}$ & 4 days & B & Yes & Sublingual & 2 & 4 days & No & 5 \\
\hline $\mathbf{4}$ & 12 years & G & No & Sublingual & 4 & 24 & No & 6 \\
\hline $\mathbf{5}$ & 2 years & G & No & Sublingual & 1.5 & 4 & No & 1 \\
\hline $\mathbf{6}$ & 3 months & B & Yes & Lingual & 1.5 & 3 & No & 11 \\
\hline $\mathbf{7}$ & 8 months & B & No & Nasal & 0.8 & 3 & No & 1 \\
\hline $\mathbf{8}$ & 2 years & B & No & Nasal & 1 & 24 & No & 2 \\
\hline $\begin{array}{l}\text { G: Girl } \\
\text { B: Boy } \\
\text { R: Recurrence }\end{array}$ & & & & & & \\
\hline
\end{tabular}




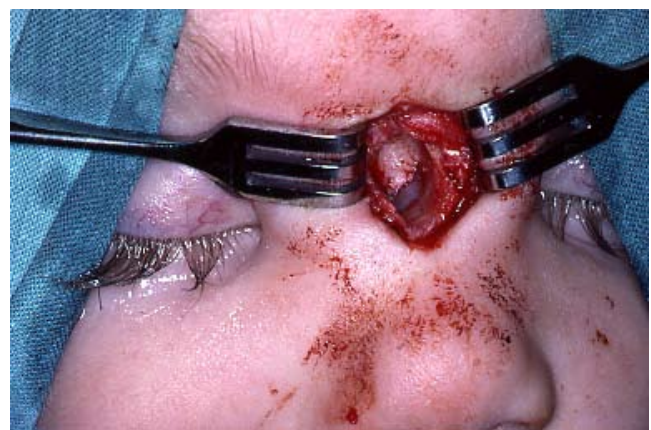

Fig. 2. Case 8: Surgical removal of a DC in the nasal dorsum.

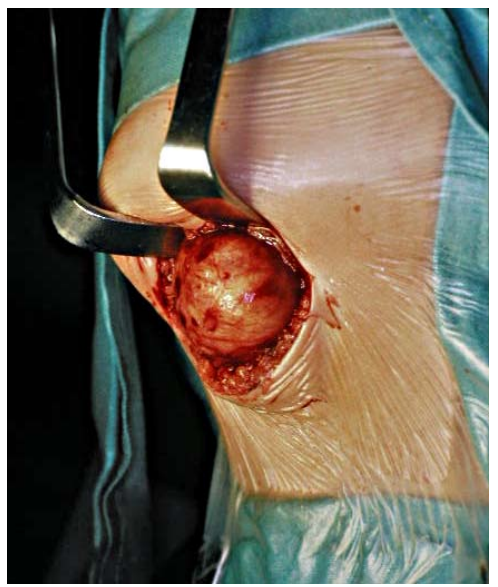

Fig. 3. Case 4: Extraoral approach to a DC below the mylohyoid muscle.

(range 0.8 to $4 \mathrm{~cm}$ ). The mean duration was 16.8 months (0-36 months). All DC were surgically removed (Fig. 2, 3). The clinical diagnosis was confirmed by pathological analysis. The mean follow up was 3.5 months (1-11 months). There were no recurrences.

\section{Discussion}

Al-Khateeb et al. (9) in 2009 conducted a retrospective study of cutaneous cysts of the head and neck in 488 patients, finding the most frequent lesion to be epidermoid cyst $(49 \%)$ followed by pilar cysts $(27 \%)$ and DC (22\%). Presentation of DC in children is rare and diagnosis at birth is unusual (2). However, in this study, 3 of the 8 cases were clinically diagnosed at birth.

With respect to sex, no significant differences have been observed (9). In this study, 3 girls and 5 boys were affected, although these data cannot be considered significant.

Regarding location of DC, the periorbital area is the most commonly affected area in the head and neck region (4, 9). Pryor et al. (4) presented 49 pediatric patients with
DC of head and neck, the most frequent location being the periorbital area (61\%). In this study, one case of DC was found in the periorbital area. DC of the nasal area appear in $6 \%$ according to Pryor et al. (4). In this study, three cases of DC appeared in the midline of the nasal dorsum. In the oral region, the floor of the mouth is the most frequent location, although the incidence is only $1.6 \%$ to $6.5 \%$ of all body DC (10). In this case series there were 3 sublingual DC, all located in the midline. The appearance of DC in the tongue is very rare (11). In this study there was one case of neonatal DC in the midline of the ventral floor of the tongue.

The size of the lesion is variable; with cases of up to 12 $\mathrm{cm}$ in diameter having been reported (12). In this study, the average diameter of the lesion was $1.7 \mathrm{~cm}$.

The treatment is surgery, removing the cyst with the entire capsule. El-Hakim and Alyamani (12), used an intraoral approach for large, deep seated non-infected lesions, obtaining good aesthetics and function. The ex

traoral approach was used in very large DC affecting the submandibular and submental space, and in cases with infection that could compromise the patient's airway. In this study, of the four DC in the oral region, 3 were surgically removed via an intraoral approach, and one extirpated extraorally through the mylohyoid muscle due to its submental location (Fig.3).

Recurrence of DC after complete removal of the lesion is rare (4). In our study there were no recurrences.

\section{Conclusion}

DC are benign, rare and do not usually present at birth in the orofacial region of pediatric patients. The floor of the mouth is the most common location in the oral cavity. Treatment is surgical removal of the lesion. Recurrence is unusual after complete surgical excision.

\section{References}

References with links to Crossref - DOI

1. Meyer I. Dermoid cysts (dermoids) of the floor of the mouth. Oral Surg Oral Med Oral Pathol. 1955;8:1149-64.

2. Teszler CB, El-Naaj IA, Emodi O, Luntz M, Peled M. Dermoid cysts of the lateral floor of the mouth: A comprehensive anatomosurgical classification of cysts of the oral floor. J Oral Maxillofac Surg. 2007;65:327-32.

3. Pollard ZF, Harley RD, Calhoun J. Dermoid cysts in children. Pediatrics. 1976;57:379-82.

4. Pryor SG, Lewis JE, Weaver AL, Orvidas LJ. Pediatric dermoid cysts of the head and neck. Otolaryngol Head Neck Surg. 2005;132:938-42.

5. Taylor BW, Erich JB, Dockerty MB. Dermoids of the head and neck. Minn Med. 1966;49:1535-40.

6. Mohta A, Sharma M. Congenital oral cysts in neonates: report of two cases. Oral Surg Oral Med Oral Pathol Oral Radiol Endod. 2006;102:e36-8.

7. Naujoks C, Handschel J, Braunstein S, Emaetig F, Depprich $\mathrm{R}$, Meyer U, et al. Dermoid cyst of the parotid gland--a case report and brief review of the literature. Int J Oral Maxillofac Surg. 2007;36:861-3.

8. Komiyama K, Miki Y, Oda Y, Tachibana T, Okaue M, Tanaka H, et al. Uncommon dermoid cyst presented in the mandible possibly 
originating from embryonic epithelial remnants. J Oral Pathol Med. 2002;31:184-7.

9. Al-Khateeb TH, Al-Masri NM, Al-Zoubi F. Cutaneous cysts of the head and neck. J Oral Maxillofac Surg. 2009;67:52-7.

10. Howell CJ. The sublingual dermoid cyst. Report of five cases and review of the literature. Oral Surg Oral Med Oral Pathol. 1985;59:578-80.

11. Gleizal A, Abouchebel N, Lebreton F, Beziat JL. Dermoid cyst of the tongue: an association of dermoid cyst with bronchogenic epithelium. J Craniomaxillofac Surg. 2006;34:113-6.

12. El-Hakim IE, Alyamani A. Alternative surgical approaches for excision of dermoid cyst of the floor of mouth. Int J Oral Maxillofac Surg. 2008;37:497-9. 